\title{
PEMUJAAN SIVA-BUDDHA DALAM MASYARAKAT HINDU DI BALI
}

\author{
I Ketut Widnya ${ }^{1}$
}

\begin{abstract}
The phenomenon of Siva-Buddha cult in Bali is more pronounced than in other places such as in East Java, South East Asian, or even in India itself, where Siva-Buddha took place as a major religious life of the masses. We found in Bali that the Sanghyang Siva-Buddha has been worshipped as Sanghyang Tunggal, i.e. One God.

As it is well know that the main problem of the syncretism of SivaBuddha Cult in the course of Indonsian's history is how to determine the proper meaning of syncretism, wether it is did happen on the level of philosophy, theology, or on the ground of social activities. In this regard, Bali has been provided rich sources to overcome of these difficulties. Many traditional's literature of Bali called lontar contains either similarities or deep ties of the two religious lifes. Moreover, it is mingled with various aspects of Balinese arts, traditions, cultures and local worship. As the result that syncretism of Siva-Buddha Cult in Bali is considered very unique in sense that the fact that the Siva-Buddha Cult is the existing religious life till mowadays. Balinese scholar, particularly the Hindu's priests has been maintain the problem through the ages, so that, literatures has been wrote and publish in accordance to the SivaBuddha Cult. But, unfortunately, as it is mainly pre-seved in the royal pamily, the masses of Bali did not aware about what does they had practiced in daily live. Actually, they had prac-tices the cult of Siva-Buddha, but they do not aware about it. Siva-Buddha Cult in Balinese traditional in regard to it main problem of syncretism on the bases of T\#ntrayana's teaching and their approach to the historical background.
\end{abstract}

Key words : Sinkretisme, Siva-Buddha

Sinkretisme Siva-Buddha di Indonesia adalah suatu gejala keagamaan yang sangat komplek. Istilah-istilah: siva-buddha tunggal dan bhinneka tunggal $i k a$, secara khusus, memang bisa memberi indikasi yang kuat tentang sinkretisme antara Sivaisme dan Buddhisme di Indonesia. Tetapi dalam arti yang lebih luas sumber-sumber sastra Jawa Kuna yang memuat istilah-istilah tersebut secara keseluruhan tidak berbicara tentang kemanunggalan di

${ }^{1}$ I Ketut Widnya adalah Doesn Fakultas Brahma Widya, Institut Hindu Dharma Negeri Denpasar. 
antara kedua sistem keagamaan tersebut. Para sarjana, peneliti dan pemerhati, telah mengkaji masalah ini dari berbagai sudut pandang. Tetapi masalah Siva-Buddha tidak sesederhana seperti yang diperkirakan sebelumnya. Kebanyakan para sarjana menganggap bahwa masalah Siva-Buddha sudah selesai dengan mengutip sumber-sumber yang terbatas dalam kesusastraan Jawa Kuna. Masalah Siva-Buddha bukan terjadi karena diambil begitu saja melalui sumber-sumber arkeologi maupun sumber-sumber sastra. Keberadaannya dalam panggung sejarah karena kontribusi yang diberikan oleh para sarjana, baik para orientalis barat, sarjana India maupun sarjana Indonesia. Itulah sebabnya masalah Siva-Buddha ini menjadi semakin komplek karena diwarnai oleh silang pendapat para sarjana.

Kompleksitas permasalahan tersebut sudah tampak sejak di India, yaitu dengan adanya kenyataan "saling menukar" dewa-dewa di antara agama Hindu, Buddha dan Jaina. Dewa-dewa Hindu seperti Pārvatī dan Indra ditemukan di antara dewa-dewa Jaina, demikian juga dewa Ga<apati, Saraswatī, Mahākāla, Nīlaka<tha, dan sebagainya, terkenal di antara dewa-dewa Buddha. Sementara Hindu meminjam dewa-dewa Buddha seperti Mahācīnatārā, Janguli dan Vajrayoginī di bawah nama Tārā, Manasā dan Chinnamastā. Kenyataan ini menyulitkan para peneliti untuk memberi batasan yang tegas mengenai sinkretisme antara Sivaisme dan Buddhisme. Di Indonesia, kesusastraan Jawa Kuno, tidak hanya berbicara tentang penyamaanpenyamaan yang terbatas antara ]iva dan Buddha, melainkan juga diantara kelompok-kelompok dewa dalam agama Hindu dan Buddha, di samping penyamaan dewa-dewa dalam intern agama Hindu dan intern agama Buddha secara terpisah. Buddha kadang-kadang disamakan dengan Visnu. Di tempat lain Buddha disamakan dengan Brahma, atau Visnu disejajarkan kedudukannya dengan ]iva (Harihara).

Tulisan-tulisan tentang Siva-Buddha, baik berupa artikel maupun hasil-hasil penelitian, sudah cukup banyak dipublikasikan. Namun, suatu gejala yang aneh bahwa di Bali sendiri, umat Hindu yang memuja tuhan "Siva-Buddha " sebagai Sanghyang Tunggal, kebanyakan belum memahami realitas ini. Padahal teks-teks yang menguraikan tentang sinkretisme Siva-Buddha di Bali terus bermunculan sampai pada zaman modern ini. Lebih dari itu, hasil penelitian menunjukkan, gejala sinkretisme Siva-Buddha di Bali merupakan yang terbesar dibanding masa-masa sebelumnya, baik di Jawa Timur (pada zaman Majapahit), maupun di India (pada Dinasti P\#la). Kenyataan ini menuntut adanya penelitian yang lebih mendalam dan kom-prehensif mengenai eksistensi Siva-Buddha dalam realitas kehidupan umat Hindu di Bali. Penelitian ini akan memfokuskan kajian pada dinamika atau evolusi Siva-Buddha dalam ajaran Tantra yang menjadi medium penyatuan Siva-Buddha di Bali. Dengan fokus kajian 
tersebut, diharapkan mampu memberi gambaran tentang eksistensi SivaBuddha dalam realitas masya-rakat umat Hindu di Bali.

\section{SEJARAH RINGKAS Siva-Buddha}

Studi tentang Siva-Buddha untuk pertama kali dilakukan dalam lapangan arkeologi pada tahun 1823(Crawfurds,1985:VOL I-III). Dalam lapangan arkeologi terjadi silang pendapat antara John Crawfurds dengan Brian Houghton Hodgson. Crawfurds mengklaim bahwa Buddhism yang benar tidak lain dari Sivaisme berdasarkan pada bukti yang tak dapat diragukan mengenai hadirnya Dewa Perusak dalam setiap Vihara-Vihara Bud dha di Nepal. Sedangkan Brian Houghton Hodgson (1827) mengatakan sebaliknya, bahwa bukti-bukti itu tidak relevan dengan Sivaisme dan dalam kenyataannya tidak mengindikasikan percampuran di antara kedua agama tersebut. Kemudian pada tahun 1888, studi tentang Siva-Buddha ini boleh dikatakan beralih dari lapangan arkeologi ke lapangan sastra, setelah Kern mempublikasikan artikelnya: "Regarding Merging of Śaivism and Buddhism in Java in Connection with the Ancient Javanese Poem Sutasoma". Suatu hal yang mengejutkan bahwa data-data arkeologi ternyata gayut dengan teks-teks sastra. Dalam lapangan sastra, studi Siva-Buddha lebih banyak menggunakan sumber-sumber atau teks sastra Jawa Kuna. Dalam lapangan studi ini tekanan khusus dilakukan untuk mengamati percampuran Siva-Buddha melalui pendekatan teologi, kebahasaan dan juga budaya lokal. Namun, para sarjana, tetap belum puas dengan kesimpulan-kesimpulan yang telah dicapai melalui studi tersebut. Masalah Siva-Buddha memang belum sepenuhnya tuntas diteliti.

Salah satu yang belum tuntas itu adalah pendekatan sejarah, khususnya untuk menelusuri dinamika atau evolusi atas percampuran Siva-Buddha dari waktu ke waktu. Dengan asumsi bahwa tingkat percampuran kedua aga ma tersebut tidak sama kohesitasnya pada setiap zaman. Artinya, sinkretisme tersebut mengalami evolusi dari satu zaman kepada zaman berikutnya sampai kemudian pada suatu zaman tertentu ada momentum sejarah yang membuatnya menjadi semakin kuat, semakin rekat, sehingga Siva-Buddha , muncul ke panggung sejarah sebagai agama tunggal. Sebagaimana diketahui momentum itu muncul di Jawa Timur pada Zaman Majapahit. Pertanya annya: mengapa muncul di Jawa Timur, padahal Sivaisme (agama Hindu) dan Buddhisme, sudah masuk ke Indonesia sebelum kejayaan kedua agama itu mencapai puncaknya di Jawa Timur. Pasti ada pra-kondisi yang mendorong percampuran kedua sistem agama tersebut, sebagaimana halnya kondisi Siva-Buddha di Bali yang semakin mantap karena stimulasi dari tradisi Jawa Timur. Dalam sejarah kebudayaan Indonesia, evolusi Siva-Buddha di-bagi menjadi tiga phase, yaitu phase pertama meliputi evolusi sebelum za-man Majapahit; phase kedua pada zaman Majapahit (1292-1500); dan phase ketiga setelah zaman Majapahit terutama perkembangan kedua sistem 
keaga maan tersebut di Bali. Pada phase pertama, yaitu sebelum zaman Majapahit tingkat sinkretisme antara Sivaisme dan Buddhisme belum menunjukkan gejala penyatuan yang kuat sehingga perbedaan antara Sivaisme dan Bud- dhisme masih dapat diperlihatkan. Sedangkan pada phase kedua, yaitu pada zaman Majapahit, sinkretisme antara kedua agama tersebut menunjukkan tingkat penyatuan yang semakin kuat karena beberapa alasan seperti peran raja yang menganut kedua agama tersebut, berkembangnya ajaran tantra yang mempengaruhi baik Sivaisme maupun Buddhisme, inter marriage, dan persamaan-persamaan antara kedua sistem tersebut baik dalam tataran philosophy, etika maupun upacara keagamaan, di samping sosial keagama-an seperti kerjasama dalam mendirikan bangunan suci. Sedangkan phase ketiga, yaitu evolusi Siva-Buddha setelah Zaman Majapahit, khususnya di Bali, menunjukkan tingkat hubungan yang semakin luluh, seperti ditunjuk-kan oleh kenyataan dimana ]iva dan Buddha dipuja Di dalam Padmasana sebagai Tuhan yang satu yang disebut Sanghyang Tunggal.

Pertanyaan yang muncul: apakah sinkretisme ]iva Buddha ini merupakan produk asli Indonesia? Masalah ini sebenarnya dapat ditelusuri sampai ke asal mula kedua agama tersebut, Hindu dan Buddha, yaitu India. Di India, percampuran Siva-Buddha mulai menunjukkan jati dirinya bersamaan dengan berkembangnya ajaran Tantra pada dinasti Pala (dari abad 811 Masehi) di Bengal dan Bihar pada dinasti Bhumakaras (736-940 M) di Orissa. Tanda-tanda awal percampuran antara Śaktisme, Śivaisme dan Buddhisme bisa ditemukan di Mandir Vetal, yaitu tempat suci untuk memuja Sakti. (Das, 2003:70). Menurut R.C. Sharma (2004: 10) percampuran antara mazab Śiva and Buddha di India merupakan hasil dari interaksi yang diinginkan (interaction of willing), sehingga unifikasi tersebut menghasilkan hubungan yang damai dan harmonis. Interaksi yang tidak diinginkan atau interaksi yang dipaksakan akan menghasilkan ketidak-harmonisan. Dalam sejarah evolusi agama Hindu dan Buddha di India, tidak selalu terjadi hubungan yang harmonis di antara kedua agama tersebut. Ada kalanya, interaksi di antara kedua agama tersebut, justru menyebabkan agama Buddha mengalami kemerosotan (decline). Khususnya pada akhir zaman pertengahan (medieval period) kebencian kaum Brāhmaṇas terhadap pengikut Buddha dianggap salah satu faktor penyebab kemerosotan agama Buddha di India. Kurangnya perlindungan terhadap pengikut Buddha dari raja-raja Hindu juga memegang peranan penting atas kemerosotan agama Buddha di India, selain karena berkembangnya ajaran Tantra.

Di Nepal, gejala percampuran Siva-Buddha , dapat ditelusuri melalui tempat suci Pasupathinath Mandir. Ini adalah salah satu tempat suci terbesar di Nepal, dimana ]iva dipuja sebagai pelindung semua makhluk hidup atau Pashupati. Sejarah pemujaan Pashupati di lembah Himalaya ini sduah ada 
sejak abad ke 3-4 M, sebagaimana dijelaskan dalam prasasti dan sumbersumber sastra. Pada bagian uttama mandala (sanctum sancturium) dari Pashupatinath Mandir terdapat ]ivalingga. Pada setiap bulan Juli, yaitu pada Srawana Purnima, umat Buddha Newar di Lembah Kathmandhu, memuja Pashupatinath sebagai Bodhisattva $\exists$ valokite $\perp$ vara. Mereka memuja ]ivalingga dengan menghiasi bagian kepala ]ivalingga tersebut dengan mahkota. Mahkota tersebut umumnya berbentuk pendeta Buddha tantrik. Dalam Prasasti Pritivi Malla yang ditemukan di daerah Nepal bagian Barat, berangka tahun saka 1279 (1357 M), mantra Buddha "Om Mani Padme Hum" dituliskan pada bagian atas prasasti, sedangkan pada bagian bawah ditulis mantra Hindu "Om Swasti".

Sinkretisme Siva-Buddha bukanlah monopoli Indonesia. Selain di India dan Nepal, phenomena yang sama juga terjadi di beberapa Negara Asia dan Asia Tenggara, seperti Tibet dan Kamboja. Namun, gejala percampuran Śivaisme dan Buddhisme di Indonesia tidak hanya yang terbesar dalam hal pengaruhnya yang luas terhadap kepercayaan masyarakat, melainkan juga satu-satunya contoh sinkretisme yang masih tetap bertahan hidup sampai saat sekarang.

\section{PENYATUAN Siva-Buddha MELALUI AJARAN TANTRA}

Sebagian besar sarjana menerima bahwa Tantrāyana adalah faktor utama yang memberi ruang terjadinya fusi antara Sivaisme dan Buddhisme sehingga menjadi suatu mazab keagamaan yang berdiri sendiri di Indonesia. Bahkan Moens secara khusus melukiskan bahwa Tantrayana, khususnya Kālācakratantra, bertanggung jawab atas penyatuan mazab Siva-Buddha di Indonesia. (Moens,1986:9). Krom (1923:106) juga berpendapat bahwa penyatuan antara Śivaisme dan Buddhisme di Indonesia dimungkinkan karena pengaruh Tantrayana atas kedua sistem keagamaan tersebut. Zoetmulder menerima pendapat Krom tentang pengaruh Tantrayana dan menamakan phenomena ini dengan nama: 'tantirme-bhairava-bouddhique', yang ditandai dengan pelaksanaan upacara inisiasi di pekuburan dan disertai de-ngan minum darah, alkohol dan hubungan sex (Zoetmulder, 1968: 300).

Tantra adalah suatu kombinasi yang unik antara mantra, upacara dan pemujaan secara total. Ia adalah agama dan juga philosophy, yang berkembang baik dalam Hinduisme maupun Buddhisme (Murti,2003:8). Definisi tantra dijelaskan dalam kalimat ini: shasanat tarayet yastu sah shastrah parikirttitah, yang berarti, "yang menyediakan petunjuk jelas memotong (clearcut guidelines) dan oleh karena itu menuntun ke jalan pembebasan spiritual dari pengikutnya disebut sastra." Akar kata "trae" diikuti oleh suffix "da" menjadi "tra," yang berarti "yang membebaskan." Kita melihat penggunaan yang sama dari akar kata "tra" Di dalam kata mantra. Definisi mantra adalah: mananat tarayet yastu sah mantrah parikirttitah: "Suatu 
proses yang, ketika diulang ulang terus menerus Di dalam pikiran, membawa pembebasan, disebut mantra." (Anandamurti,1994:109-110)

Beberapa sarjana mencoba membagi tantra menjadi dua bagian utama, yaitu: "jalan kanan" dan "jalan kiri." Bernet Kemper berpendapat, tantra "jalan kanan" (menghindari praktek ekstrem, mencari-cari pengertian yang mendalam, dan pembebasan melalui asceticism) harus dibedakan dari "jalan kiri”(black magic dan ilmu sihir) (Kemper,1991:53). Ia kemudian menegaskan, Di dalam "jalan kanan", bhakti atau penyerahan diri memegang peranan yang sangat penting. Lebih dari itu, bhakti cenderung menolak dunia material. Sedangkan "jalan kiri” mempunyai kecendrungan yang sangat berbeda. Ia berusaha keras untuk menguasai aspek-aspek kehidupan yang mengganggu dan mengerikan seperti kematian dan penyakit. Untuk mengatasi hal tersebut, eksistensi dari kekuatan keraksasaan (demonic) "jalan kiri" membuat kontak langsung di tempat-tempat yang mengerikan seperti di pekuburan (Kemper,1991:54). Pandangan kalangan akademis ini sangat berbeda dengan pandangan dari praktisi tantra. Para praktisi tantra pada umumnya menolak pembagian tantra atas tantra positif dan negative dan menekankan pada metode untuk mentransformasikan keinginan. Lama Thubten Yeshe, seorang praktisi Tibetan tantra, mengatakan, tantra menggunakan pendekatan yang berbeda. Meskipun tantra mengakui bahwa khayalan seperti keterikatan kepada keinginan adalah sumber dari penderitaan dan oleh karena itu harus di atasi, namun ia juga mengajarkan keahlian untuk menggunakan energi dari khayalan tersebut untuk memperdalam kesadaran kita sehingga menghasilkan kemajuan spiritual. Seperti mereka yang dengan keahliannya mampu mengangkat racun tumbuh-tumbuhan dan menjadikannya obat yang mujarab, seperti itu pula seorang yang ahli dan terlatih dalam praktek tantra, mampu memanipulasi energi keinginan bah-kan kemarahan menjadi mapan. Ini sungguh-sungguh sangat mungkin dilakukan." (Yeshe, 2001: 18).

Dalam arti tertentu, tantra merupakan suatu teknik untuk mempercepat pencapaian tujuan agama atau realisasi sang diri dengan menggunakan berbagai medium seperti mantra, yantra, mudra, mandala, pemujaan terhadap berbagai dewa dan dewi, termasuk pemujaan kepada makhluk setengah dewa dan makhluk-makhluk lain, meditasi dan berbagai cara pemujaan, serta praktek yoga yang kadang-kadang dihubungkan dengan hubungan sexual (Dasgupta,1974:2). Elemen-elemen tersebut terdapat dalam tantra Hindu maupun Buddha. Kesamaan teologi ini menjadi faktor penting yang memungkinkan tantra menjadi salah satu medium penyatuan antara ]ivaisme dan Buddhisme di Indonesia.

Hubungan sex dalam Tantra, seperti diperkirakan oleh Dasgupta merupakan penyimpangan dari konsep awal Tantra. Konsep awal Tantra meliputi elemen-elemen seperti yang disebutkan di atas, yakni: mantra, 
yantra, mudra, dan yoga. Penyimpangan tersebut terjadi karena penggunaan "alat-alat praktis" (practical means) dalam Tantra Buddha yang berdasarkan prinsip-prinsip Mahāyāna dimaksudkan untuk merealisasikan tujuan tertinggi (Dasgupta,1974:1). Dengan kata lain, tujuan tertinggi baik tantra Hindu maupun Buddha, adalah tercapainya keadaan sempurna dengan penyatuan antara dua praktek ( $p r a j \tilde{n} \bar{a}$ and upāya) serta merealisasikan sifat non-dual dari Realitas Tertinggi. H.B. Sarkar menyatakan hubungan sexual dalam Tantra lebih diarahkan untuk mengontol kekuatan alam dan bukan untuk mencapai pembebasan (Sarkar,1980:71). Ia mengatakan, secara umum, tradisi Indonesia, membagi tujuan hidup manusia menjadi dua: pragmatis and idealistis. Mengontrol kekuatan alam adalah salah satu tujuan pragmatis. Hal ini biasanya dilakukan oleh raja yang mempraktekkan sistem Kālācakrayāna dalam usaha melindungi rakyatnya, memberikan keadilan, kesejahteraan dan kedamian.

Di Indonesia dikenal tiga jenis tantra, yaitu: Bhairava Heruka di Padang Lawas, Sumatra Barat; Bhairava Kālācakra yang dipraktekkan oleh raja K[tanegara dari Singasari dan Ādityavarman dari Sumatra yang se-zaman dengan Gajahmada di Majapahit; dan Bhairava Bhima di Bali. Arca Bhairava Bima terdapat di Pura Edan, Bedulu, Gianyar, Bali. Menurut Prasasti Palembang (684 M), Tantrayana masuk ke Indonesia melalui kerajaan Śrivi jaya di Sumatra pada abad ke-7 (Purwita,2000:2). Kālacakratantra memegang peranan penting dalam unifikasi Sivaisme dan Buddhisme, karena dalam tantra ini, Śiva and Buddha, diunifikasikan menjadi Śivabuddha. Kon sep Ardhanarisvarī memegang peranan yang sangat penting dalam Kālācakratantra. Kālācakratantra mencoba menjelaskan penciptaan dan kekuatan alam dengan penyatuan Dewi Kali yang mengerikan, tidak hanya dengan Dhyāni Buddha, melainkan juga dengan Ādi Buddha Sendiri. Kālācakratantra mempunyai berbagai nama dalam sekta tantra yang lain, seperti $\mathrm{He}$ wajra, Kālācakra, Acala, Cakra Sambara, Vajrabairava, Yamari, Candama harosana dan berbagai bentuk Heruka (Moens, 1986:9).

Di dalam Tantrayana, ritual adalah elemen utama untuk merealisasikan Kebenaran Tertinggi. John Woodroffe mengatakan, ritual adalah sebuah seni keagamaan. Seni adalah bentuk luar materi sebagai ekspresi dari idea-idea yang berdasarkan intelektual dan dirasakan secara emosional. Seni ritual berhubungan dengan ekspresi idea-idea dan perasaan tersebut yang secara khusus disebut religious. Ini adalah suatu cara, dengan mana kebenaran religious ditampilkan, dan dapat dimengerti dalam bentuk material dan simbol-simbol oleh pikiran. Ini berhubungan dengan semua manifestasi alam dalam wujud keindahan, dimana untuk beberapa alasan, $\mathrm{Tu}$ han memperlihatkan Diri Beliau Sendiri. Tetapi ini tidak terbatas hanya untuk tujuan itu semata-mata. Artinya, dengan seni religious sebagai alat, pikiran ditransformasikan dan disucikan (Woodroffe, 1994: 9). 
Mazab Siva-Buddha dengan pengaruh khusus Kālācakratantra da-pat dilihat pada tinggalan-tinggalan arkeologi, seperti di Candi Jawi. Pra-panca dalam Nāgarakěrtāgama Bab 56, ayat 1 dan 2, melukiskan monumen ini dengan sangat indah. Bagian bawah candi, yaitu bagian dasar dan badan candi, adalah Śivaistis dan bagian atas atau atap, adalah Buddhistis, sebab Di dalam kamar terdapat arca Śiva dan di atasnya di langit-langit terdapat sebuah arca $\mathrm{Ak}$ \{obhya. Inilah alasannya mengapa Candi Jawi sangat tinggi dan oleh karena itu disebut sebuah Kirtti (Bosch, 1925: 31).

Dalam tantra Hindu prinsip metaphisik Śiva-Śakti dimanifestasikan di dunia material ini dalam wujud laki dan perempuan; sedangkan dalam tantra Buddha pola sama diikuti, dimana prinsip-prinsip metaphisik Prajñā and Upāya termanifestasikan dalam wujud perempuan dan laki. Tujuan tertinggi dari kedua mazab tantra ini adalah penyatuan sempurna, yaitu penyatuan antara dua aspek dari realitas dan realisasi dari sifat-sifat non-dual dari roh dan non-roh.

Prinsip-prinsip tantra secara fundamental sama dimana-mana. Perbedaan-perbedaan kecil yang barangkali ada, hanyalah perbedaan pada nada dan warna. Dalam tantra Hindu, nada dan warna tersebut, diisi oleh ideaidea filsafat, agama dan praktek-praktek agama Hindu; sedangkan tantra Buddha diisi oleh ajaran-ajaran agama Buddha (Dasgupta, 1974: 4).

Sehubungan dengan tantra Hindu dan Buddha ini, H.B. Sarkar mengatakan, mistik yang lebih tua dan ritual dengan praktek-praktek shamanisme diperlakukan dan dimodifikasi dengan perhiasan-perhiasaan baru pemujaan yang didominasi oleh ma<*ala, mantra, mudr\#, abhiseka, dan sebagainya. Disini, baik tantra Buddha maupun tantra Hindu sebagian besar menggunakan simbul-simbul luar dan pola yang sama dalam penyelenggaraaan ritual, tetapi isi dan objek dari kedua tantra itu berbeda secara keseluruhan. Sebab, para sadhaka Buddha melalui praktek tantra menginginkan pembebasan dari ikatan dunia material dan tenggelam kedalam kebahagiaan abadi, sedangkan tantra Śaiva ingin mengontrol dunia material (Kumar, 2001:72).

Dengan kenyataan-kenyataan tersebut tidak mengherankan apabila Śivaisme dan Buddhisme bisa mencapai penyatuan yang begitu dalam melalui medium ajaran Kālācakratantra. Alasan atas kuatnya penyatuan tersebut juga dapat ditelusuri melalui fakta sejarah bahwa awal mula kehadiran Kālācakratantra di antara pemeluk Hindu dan Buddha adalah untuk melakukan perlawanan terhadap pengaruh kekuasaan Islam. Biswanath Banerjee (1999:265) mengatakan, penyatuan dewa-dewa dan dewi-dewi Hindu mencapai puncaknya pada waktu berkembangnya sistem Kālācakra. Faktor utama yang mendorong berkembangnya kecendrungan berkompromi antara Buddhisme dengan berbagai sekta dalam agama Hindu, dapat dilacak keberadaaannya dengan kehadiran agama dan kebudayaan Islam. Ini dapat dipe- 
lajari melalui teks-teks Kālacakra bahwa Buddhisme sedang mengalami masalah sosial atas sergapan infiltrasi kebudayaan Smitic dan untuk melakukan perlawanan atas berkembangnya pengaruh kebudayaan asing tersebut, mereka melakukan kerjasama dengan umat Hindu. Maksud memperkenalkan sistem K\#lacakra adalah untuk melindungi umat Buddha dan Hindu dari konversi (pengalihan agama) ke agama Islam. Dengan maksud untuk menghentikan kerusakan akibat kebudayaan asing, para pemimpin agama Buddha melakukan inter-marriage dan inter-dining antara keluarga Buddha dan Hindu, dan akhirnya mereka tertarik untuk berlindung dibawah panji satu Tuhan Kālacakra, yang diterima di antara mereka sebagai Tuhan Yang Maha Esa. Bagi mereka yang sedang menghadapi darurat perang adalah sangat mungkin untuk menyatukan berbagai kelompok religius dan berjuang dibawah kepemimpinan Tuhan Kālacakra untuk melawan pengaruh asing. Perkembangan mazab ini dengan penyatuan dewa-dewa Hindu yang begitu kuat Di dalam ma<*ala Kãlācakra menyebabkan terjadinya fusi kebudayaan dan mereka akhirnya bersatu menghadapi bahaya yang segera terjadi karena infiltrasi Islam. Selanjutnya dicoba melakukan penyatuan di antara semua pengikut Brahmā, $\mathrm{Vi}\{<\mathrm{u}$, Śiva dan termasuk orang-orang suci mereka di dalam satu keluarga Vajrakula, dengan empat inisiasi utama Di dalam Kāla-cakra, yaitu menghilangkan semua perbedaan Di dalam ras, kelas, syahadat dan tradisi.

Selain pendekatan sejarah dan teologi, juga banyak dilihat penyatuan Siva-Buddha karena persamaan philosophy. Ida Bagus Made Mantra menga takan bahwa persamaan fundamental dalam teori manifestasi antara Śiva-isme, khususnya Śiva Siddhānta, dan Buddha Mahāyāna bertanggung jawab atas berkembangnya mazab Siva-Buddha (Mantra, 1955:255). Untuk tujuan ini ia memberikan uraian yang sangat panjang (Mantra, 1955:255258).

Dalam filsafat Śiva Siddhānta terdapat tiga tattva (realitas): Śivatatva, Sadāsiva-tattva, dan Mahěśa-tattva. Ketiga tattwa tersebut berturut-turut memiliki sifat-sifat sebagai berikut: Niskalā, Sakalā-niskalā dan Sakalā. Ketiga tattvas dari Śaiva Siddhānta itu berkaitan dengan empat Kāya dari filsafat Buddha Mahāyāna. Keempat kayā itu adalah: Svabhāva-kāya, Dhar ma-kāya, Sambhoga-kāya and Nirmaya-kāya.

Niskalā artinya tanpa bentuk, dan aspek ini merupakan ciri dari Śivatatva. Śiva dalam posisi tertinggi adalah tanpa bentuk atau tanpa atri-but atau dalam suatu keadaan entitas tanpa bentuk yang tak dapat dibedakan (undifferentiated formless entity). Dalam kedudukan ini semua bentukbentuk yang diciptakan dari corpo-realitas menyatukan badan mereka Di dalam penyebab awal (Primeval Cause). Keadaan ini merupakan keadaan damai yang tidak dapat dimengerti. Dalam kedudukan ini pula, Realitas Tertinggi, dipahami tanpa awal dan akhir, meresap kedalam seluruh alam 
semesta, tak terpisahkan dan tidak dapat dibandingkan. Inilah keadaan yang dipahami dalam keadaan Niskalā.

Svabhāvaka-kāya adalah kesadaran murni, bersih dari semua kekotoran subyektif dan obyektif, passif, tanpa aktifitas, meliputi alam semesta, penyatuan kosmis dari kebijaksanaan yang tak terbatas dan kebajikan, memiliki kasih sayang universal, prinsip-prinsip dalam (inner principle) dari semua Dharma. Sifat-sifat tersebut adalah sifat dari svabhāvaka-kāya yang diidentifikasikan dengan Buddha. Ke-empat kaya tersebut diklasifikasikan menjadi dua group. Group pertama, Svabhāvaka-kāya dan Dharma-kāya, yang bersifat kesucian sempurna, passif Di dalam prinsip-prinsipnya, dan group kedua, muncul di dunia ini untuk dipertunjukkan. Disini perlu digaris-bawahi bahwa Svabhāvaka-kāya kadangkala tidak dijelaskan, dan oleh karena itu, hanya Dharma-kāya mewakili prinsip murni dan passif.

Mazab Shinghong dari Buddha Mahāyāna di Jepang juga mempunyai teori manifestasi dari penyatuan alam (manifestation of the cosmic unity) yang kurang lebih memiliki persamaan dengan Śiva Siddhānta. Menurut mazab ini, Tathāgata Mahavairocana atau Dahrma-kāya mempunyai dua perwujudan, yaitu Garba-dhātu (matrix element), dan Vajra-dhātu (thunder element). Garba-dh\#tu memiliki karakter: a) Meditasi Agung, b) Kebijaksanaan, c) Kasih sayang, dan masing-masing dari ketiganya diatributkan kepada Buddha, Vajra and Padma. Buddha bersesuaian dengan Tathāgata-Mahavairocana yang menandakan pengetahuan sempurna. Yang kedua bersesuaian dengan Vajra-sattva menandakan suatu kebijaksanaam, pasti dalam sifat-sifatnya dan menghancurkan semua penderitaan. Yang ketiga bersesuaian dengan Avalokitěsvara menandakan pemikiran murni dari bagian dalam makhluk hidup.

Dhātu kedua, Vajra-dhātu (elemen halilintar), mempunyai lima aspek, tiga diantaranya termasuk tiga klas sebagaimana dijelaskan Di dalam Garba-dhātu, dan dua lainnya adalah Ratnānubhāva dan Karmānubhāva. Sifat-sifat Ratnānubhāva mengungkapkan kebenaran dan pembebasan sempurna dari Buddha tanpa pembatasan. Yang kelima, Karmānubhāva memperlihatkan pemenuhan dari seluruh kegiatan.

Dalam perbandingan sistem cosmology antara filsafat Buddha Mahāyāna dan Śaiva-Siddhānta, Ida Bagus Made Mantra mengatakan, bahwa keduanya mempunyai basis yang sama. Ini terlihat dari tritunggal ŚaivaSiddhānta seperti Paramaśiva, Sadāśiva dan Sadāśiva-Mahěsvara dengan bentuknya dalam Niskalā dan Niskalā-Śakalā, yang parallel dengan tritunggal Buddha, yakni: Buddha Vajrasattva dan Avalokitěsvara dengan bentuk mereka berturut-turut sebagai Dharmakāya, Sambogakāya dan Nirmānakāya (Mantra, 1955:266-267).

Di dalam Buddha Mahāyāna, keadaan tertinggi adalah Boddhi Citta atau pikiran yang tercerahkan. Boddhi Citta ini mempunyai dua elemen 
yang terdiri dari Sūnyatā, pencerahan sempurna dari sifat-sifat kesunyataan, dan kedua adalah Karunā, kasih sayang universal untuk semua makhluk hidup. Penggabungan menjadi satu dari kedua elemen tersebut (Sūnyatā and Karunā) dikenal sebagai Advaya. Di dalam ajaran Vajrayana, realisasi dari kedua elemen tersebut sangat penting. Dikatakan, keadaan Sūnyatā adalah berdasarkan pada realisasi bahwa semua benda adalah fana, tanpa roh. (transitory, non-ego). Mereka seperti khayalan dalam mimpi, dan tidak nyata. Sūnyatā diberkati dengan kesucian, tanpa eksistensi, tidak terlahirkan, dan kosong. Karu $<\bar{a}$, yang mewakili kasih sayang semesta dimaksudkan untuk menyebarkan pengetahuan yang benar kepada umat manusia. Kenginan menyebabkan manusia diikat oleh kebodohan, dan tidak bisa merealisasikan hukum tumimbal lahir karena tekanan dari kegiatan mereka. Kasih sayang menyiratkan terhilangkannya ikatan, dan menuntun mereka kepada kehidupan yang percaya dengan hukum saling ketergantungan (Pratītya-samutpāda) (Bhattacarya, 1964:102).

Sebagaimana dijelaskan di atas, penggabungan kedua elemen tersebut dinamakan advaya. Ini seperti bercampurnya garam Di dalam air, yang hasilnya berupa penghilangan dualitas sehingga memunculkan non-dualitas. Belakangan, dalam mazab Vajrayana, idea tersebut diganti dengan Ādi Bud dha and Prajña. Jadi, kedua arca ini mewakili Sunyatā and Karu $<\bar{a}$. Hubung-an di antara kedua arca tersebut dilukiskan dalam beberapa teks sebagai conjugal love (shajam prema) yang bersifat alami, dan Yuganaddha (con-jugal relation) atau dinamakan advaya, yang tidak lain dari Bod-dhi-citta dan Dharma-kāya (Dasgupta, 1974: 17, 128).

Konsep sakti dalam agama Buddha juga parallel dengan sakti dalam Śivisme. Konsep Yub-yam dalam Buddha diwakili oleh Śiva dan saktiNya, Parvati. Secara teknis, bentuk ini disebut Ardhanāriśvara-mūrti (Rao, 1916: 160). Di sini, Śiva Sendiri adalah murni dan sakti-Nya aktif, suatu kekuatan dinamis untuk membebaskan roh-roh yang terikat dari karma mereka. Uraian di atas, menunjukkan dengan jelas bahwa kesamaan dalam ajaran tantra, telah menyatukan kedua agama tersebut, Hindu (]iwaisme) dan Buddhisme, menjadi satu mazab keagamaan yang tunggal, ]ivabuddha. Dalam teks sastra Jawa Kuna kenyataan itu ber-puncak dalam sebutan " $y a$ Buddha ya Śiva", yang artinya tidak ada perbe-daan apakah anda seorang penganut ]iva atau Buddha.

\section{Pemujaan Siva-Buddha di Bali}

Di Bali, sinkretisme ]iwa-Buddha, sudah ada sejak zaman Bali Ku-no (abad 8-14 M), sebagaimana dapat dibuktikan melalui tinggalan-tinggalan arkeologi dan literatur. Prasasti Bla)jong menjelaskan bahwa raja mencari perlindungan dari Buddha untuk kesejahteraan negerinya, seperti dijelaskan dalam paragraf ini: buddhahsaranah k/tih Balidv3pa. Pada Za-man Bali 
Kuna, agama Buddha mempunyai kedudukan yang sangat kuat dalam masyarakat di Bali. Buddha dikenal dengan berbagai nama seperti Jina, ]akyamuni, dan Sogata (Sanskrit: Sugata). Prasasti Sukavana (Sukha-vana) mengandung bukti yang sangat jelas, bahwa pendeta-pendeta brahma-na diberikan nama Bhiku, seperti: Bhiku ]ivakansita, Bhiku ]ivanirmala dan Bhiku ]ivvapraj〉a. Votive-votive yang ditemukan di Bali mengandung prinsip-prinsip ajaran Buddha, seperti "ye dharm \#h hetu prabhavah". Prasasti Landih juga mengandung doa pemujaan kepada ]iva dan Buddha: Namo Jivaya, namo buddhaya. Nama-nama tempat di Bali, seperti Sukawati, Suwung, Sakenan, semuanya mengingatkan kita kepada konsep-konsep penting ajaran Buddha, seperti Sukhavati, Sunya dan ]akyamuni. Pengaruh Buddha di Bali masih sangat kuat sampai pada zaman modern ini. Bahkan motto universitas negeri terbesar di Bali, Universitas Udayana, mengambil inspirasi dari kutbah pertama Sang Buddha yang disampaikan di Taman Menjangan, Benares: dharmacakraprawartana, pemutaran roda dharma. Agama Buddha adalah yang pertama kali datang ke Bali. Sedangkan agama Hindu adalah yang pertama kali datang ke Indonesia. Dalam teks-teks lontar kita menemukan istilah-istilah kasaiwan dan kasogatan, yang semua itu memberi indikasi yang kuat tentang adanya penyatuan ]iva-Buddha di Bali. Yang sangat menarik, hampir semua arca-arca Buddha ditemukan dalam tempat suci agama Hindu. Para sarjana meyakini bahwa fakta ini bukan merupakan bukti tentang konversi agama, melainkan suatu proses penyatuan antara Sivaisme dan Buddhisme yang terjadi secara gradual dalam proses sejarah. Contoh-contoh seperti ini bisa diperpanjang dengan mengutip sumber-sumber yang lebih luas lagi.

Pada Zaman Majapahit, Bali merupakan perpanjangan birokrasi dari Majapahit. Suasana keagamaan di Majapahit secara otomatis mempengaruhi Bali. Karena itu, sinkretisme Siva-Buddha di Bali menjadi semakin kuat karena pengaruh Majapahit. Pengaruh itu dicatat dalam teks-teks sastra. Kidung Pamancangah, misalnya, memberi gambaran yang jelas tentang sinkretisme Siva-Buddha melalui pelaksanaan homa yaj $>$ a. Dijelaskan, pada tahun 1578 Dalem Watur Enggong di Samprangan (Klungkung) melaksana-kan upacara homa yaj \a dalam rangka upacara Eka Dasa Rudra di Besakih. Upacara homa ini dipimpin dua orang pendeta, yaitu pendeta Buddha dan pendeta ]iva. Dari pendeta ]iva dipercayakan kepada Danghyang Nirartha, sedangkan dari pendeta Buddha diwakili oleh Danghyang Astapaka. Pada mulanya Dalem Watur Enggong meminta Danghyang Angsoka, seorang pendeta di kerajaan Majapahit, untuk mewakili pendeta Buddha dalam memimpin upacara homa tersebut. Bahkan Dalem Watur Enggong sempat mengirim utusan ke Majapahit, Jawa Timur. Tetapi setelah bertemu dengan Danghyang Angsoka, utusan itu diberi tahu bahwa putranya, Danghyang Astapaka, yang lebih ahli dalam homa yaj la, 
sudah ada di Bali. Karena itu, beliau menyarankan supaya putranya itu diminta untuk memimpin homa yaj $>$ a tersebut. Akhirnya, utusan Dalem Watur Enggong balik ke Bali, dan setelah menerima laporan dari utusan tersebut, Dalem Watur Enggong memutuskan, bahwa pemimpin homa yaj la dari pihak Buddha diwakili oleh Danghyang Astapaka. Jadi, homa yaj/a dalam rangka upacara Eka Dasa Rudra di Besakih itu, dipimpin oleh Danghyang Nirartha dan Dang-hyang Astapaka. Dalam naskah kidung ini, juga dijelaskan riwayat pelak-sanaan homa yajna itu. Dikatakan, tempat pelaksanaan homa yajna adalah Di dalam istana Samprangan, dan dalam proses pelaksanaannya, api homa yajna tidak dapat dikendalikan dan menjadi semakin besar sehingga mem-bakar gedung tempat penyelenggaraan homa yajna tersebut.

Berbeda dengan di India, yang dalam periode tertentu, Buddhisme selalu mengklaim diri lebih unggul dari Hinduisme (terutama soal filsafat), dan sebaliknya Hinduisme selalu mengklain diri lebih unggul juga dari Buddhisme. Di Bali, posisi keduanya ditempatkan dalam kedudukan yang sejajar, tidak ada yang lebih tinggi dan lebih rendah. Ini terbukti dari pengakuan para pendeta di Bali, bahwa para pendeta ]iva tidak akan sempurna jika tidak mengetahui ajaran agama Buddha, dan sebaliknya pendeta Buddha juga mengakui tidak akan sempurna jika tidak mengetahui ajaran ]iva. Air suci "tirtha Buddha" dari pendeta Buddha dipakai oleh penganut ]iva untuk penyucian roh orang yang meninggal, dan sebaliknya air suci pendeta ]iva dipakai oleh penganut Buddha untuk tujuan yang sama. Meskipun Sivaisme dan Buddhisme ditempatkan dalam kedudukan yang sejajar, namun beberapa teks juga bias dengan wawasan ini.

Sebagaimana diketahui, masalah sinkretisme Siva-Buddha sebagian besar diuraikan dalam teks-teks Buddha, seperti Sutasoma, Sanghyang Kamahanikan, Bubhuksah dan sebagainya. Ada kecenderungan dalam teksteks Buddha tersebut, untuk menempatkan Buddhisme dalam posisi superior dibandingkan dengan ]ivaisme. Namun, belakangan di Bali, teks-teks yang bercorak Sivaisme justru menempatkan ]iwaisme lebih unggul dibandingkan dengan Buddhisme. Salah satu contohnya adalah Tutur Candrabherawa. Pengawi dalam naskah ini menceritakan tokoh Yudisthira yang menganut ajaran Karma Sanyasa, dan Candrabherawa yang menganut ajaran Yoga Sannyasa. Dalam naskah disebutkan bahwa ajaran Karma Sanyasa berpusat pada pembangunan tempat suci, persembahyangan sesaji yang dikenal dengan Panca Yajna, dan penyembahan kepada Dewa. Sedangkan ajaran Yoga Sanyasa adalah sebaliknya, tidak ada tempat suci, tidak ada persembahan, tidak ada persembahan kepada Dewa. Yang dipuja adalah Sanghyang Adhi Buddha dengan mempelajari Bajradhara. Tidak ada Dewa diluar (tempat suci), tetapi ada dalam diri dan banyak persembahan yang 
mengantar ke Neraka. Maka itu, Dewa dalam badan harus dipuja, agar lepas dari sorga dan neraka, tidak terlahirkan lagi.

Ajaran yoga sanyasa yang dianut oleh Candrabherawa (tantra Buddha) seperti dijelaskan di atas, sama persis dengan ajaran tantra sebagaimana dijelaskan oleh S.B. Dasgupta, berikut ini: "Tdak ada perbedaan prinsip antara tantra Hindu dan Buddha. Lepas dari banyaknya perbedaan, secara esensial, tantrayana, baik Buddhisme maupun Hinduisme, menekankan pada suatu fostulat fundamental, bahwa kebenaran terletak di dalam badan manusia; atau, dengan kata lain, badan manusia adalah medium yang paling baik untuk merealisasika kebenaran. Penekanan khusus pada pentingnya badan manusia sebagai kebenaran tertinggi, dan pada saat yang sama seba-gai medium terbaik untuk merealisasikan kebenaran, merupakan pendekat-an berbeda, yang membuat sadhana tantra berbeda dari semua jenis sadhana yang lain. Namun demikian, baik tantra Hindu maupun Buddha, keduanya secara fundamental mempunyai ciri umum mengenai prinsip-prinsip teologi yang bersifat dualitas dalam non-dualitas. Keduanya mengakui bahwa realitas non-dual yang tertinggi mempunyai dua aspek Di dalam sifatnya yang fundamental, yaitu negative (nivrti) dan positif (pravr-ti), atau sifat-sifat statis dan dinamis. Kedua aspek dari realitas tersebut diwakili oleh Siwa dan Sakti dalam agama Hindu, sedangkan dalam agama Buddha diwakili oleh Prajna dan Upaya (Sunyata dan Karuna)".

Apabila ajaran dalam Tutur Candrabherawa di atas, dianalisis menurut kerangka ajaran agama Hindu dan Buddha secara keseluruhan, maka Karma Sannyasa tidak lain dari ajaran Eksoteris yang menekankan ajarannya keluar badan. Sedangkan, ajaran Yoga Sanyasa dapat disejajarkan dengan ajaran Esoteris yang memusatkan ajarannya kedalam diri, kedalam badan. Secara tidak langsung Tutur Candrabherawa menempatkan Karma Sanyasa (eksoteris) lebih superior atau lebih unggul dibandingkan dengan Yoga Sanyasa, sebagaimana tampak dalam plot keberhasilan Yudisthira menangkap roh Chandrabherawa dan membawanya kembali ke Dewantara, dan termasuk adegan yang menyusul berikutnya dimana Chandrabherawa menyembah Yudisthira. Kecendrungan ini merupakan hasil dari kuatnya pengaruh ritual dan upakara yaj $>$ a dari ajaran ]aiva-Siddhanta di Bali.

Jadi, dalam arti khusus, agama Hindu sebagaimana yang dipraktekkan oleh umat Hindu di Bali sampai saat ini adalah mazab Siva-Buddha. Tetapi praktek Siva-Buddha sebagai ajaran tantra hanya dilaksanakan oleh kalangan pendeta secara terbatas. Umat kebanyakan, tidak hanya tidak mem praktekkan (karena mereka tergantung kepada pendeta), melainkan juga sama sekali buta dan tidak mengetahui tentang ajaran-ajaran yang berkaitan dengan sinkretisme Siva-Buddha ini. Hal ini dapat dimaklumi, karena agama Hindu dan Buddha, baik di Indonesia maupun di India, pada mulanya berkembang Di dalam lingkungan kerajaan. Dalam penger-tian ini, raja, 
atas saran penasehat kerajaan (purohita) melaksanakan ajaran Siva-Buddha , sedangkan rakyat hanya mengikuti apa yang dilaksanakan atau diperintahkan oleh raja. Kondisi ini bertahan terus ketika kita telah memasuki zaman post-modern, dimana fenomena keagamaan secara keseluruhan, termasuk agama Hindu dan Buddha, berkembang menjadi agama massa.

Memang ajaran yang dipraktekkan dalam tantra Siva-Buddha disuplai oleh ajaran agama Buddha dan Hindu (]ivaisme) secara bersama-sama. Dalam arti ini, mazab Siva-Buddha kadang-kadang dibedakan dari mazab tantra ]iva maupun mazab tantra Buddha. Tetapi dengan kecendrungan perkembangan terakhir di Bali, terutama setelah zaman kemerdekaan, apa yang disebut dengan Siva-Buddha tidak lain dari sub-sistem dari agama Hindu. Secara formal, para pendeta ]iva maupun pendeta Buddha di Bali, adalah beragama Hindu, sebagaimana tercantum dalam KTP mereka. Sejarahnya bisa ditelusuri setelah terbentuknya pemerintahan Indonesia setelah zaman kemerdekaan. Setelah Indonesia merdeka, pemerintah menetapkan lima agama: Hindu, Buddha, Islam, Katolik dan Kristen. Semua penduduk Indonesia diharuskan memilih salah satu dari lima agama tersebut. Menghadapi kenyataan ini, para pendeta Buddha dan para pengikutnya di Bali tidak memilih masuk menjadi agama Buddha, melainkan mengikuti rekan mereka para pendeta ]iva menjadi pemeluk agama Hindu. Sejak itu, para pendeta Buddha dan pengikutnya menjadi pemeluk agama Hindu.

Apapun penilaian yang diberikan oleh berbagai kalangan atas sinkretisme Siva-Buddha ini, satu hal yang pasti, mazab Śiva- Buddha ini adalah suatu mazab yang unik, karena Di dalamnya mengadopsi kepercayaan kuna dan kepercayaan lokal yang sangat komplek. Di dalamnya termasuk elemen-elemen pemujaan kepada leluhur, ibu bhumi, pohon, roh burung, binatang, kekuatan magis, spirit dan hantu-hantu. Dalam batas-batas tertentu, beberapa dari elemen tersebut, terutama kepercayaan lokal seperti pemujaan kepada leluhur, telah dihapuskan dalam agama Buddha, seperti terjadi dalam sejarah masuknya agama Buddha ke Srilanka.

\section{SIMPULAN}

Siva-Buddha dengan berbagai varian terminologi yang diberikan untuk menamakannya, merupakan suatu gejala keagamaan yang sangat komplek. Para tataran teoritis, ajaran tantra menjadi medium yang menya-tukan kedua agama tersebut, sehingga para pendeta Buddha dan pendeta ]iva di Bali menganggap diri mereka masing-masing tidak sempurna apabila mereka tidak menguasai ajaran dari kedua agama tersebut. Penyatuan-penyatuan itu, sebagaimana dibuktikan dalam sejarah, tidak terjadi dalam seluruh aspek keagamaaan dari kedua agama tersebut, melainkan terjadi hanya pada aspek teologis secara dominan, seperti "penyatuan-penyatuan di antara zat 


\section{Pemujaan Śiva-Buddha dalam ... (I Ketut Widnya)}

yang tertinggi". Pada tataran praksis, realitas pemujaan Siva-Buddha di Bali tidak lebih dari sub-sistem agama Hindu, hal ini terbukti, tidak hanya ka-rena domain ritual dan upakara sebagai akibat kuatnya pengaruh ]iwa Sid-dhanta, melainkan suatu fakta bahwa para pendeta dari kedua agama terse-but menganut agama Hindu secara formal. Hanya dalam beberapa hal kita melihat pengaruh Buddha yang disatukan dengan aspek ajaran ]iva Siddhanta, seperti dalam penggunaan genta dan ketu, demikian juga perbedaan dalam menggelung rambut, dan penggunaan beberapa mantra. Semua ini menunjukkan kompleksitas masalah dalam Siva-Buddha . Karena itu, penelitian lanjutan mengenai masalah Siva-Buddha, tetap harus dilakukan.

\section{DAFTAR RUJUKAN}

Anandamurthi, Shriji. 1994. Discourses of tantra,

Bosch. 1925. De Inscriptie van Kělurak,

Crawfurd, John. 1985. History of the Indian Archipelago, Vol. I-III. Delhi: B.R. Publishing Corp.

Das, H.C., (ed). 2003. The Cultural Heritage of Kurda. Bhubanesvar.

Dasgupta, S.B. 1974. An Introduction to Tantric Buddhism. Calcutta: University of Calcutta.

Goris, R. (texts) and Dronkers, P.L. (Photography). 1953. Bali/Atlas Kebudajaan/ Cults and Customs (Cultuurgeschiedenis in beeld). Jakarta: Pemerintah Republik Indonesia/Government of the Republic Indonesia.

Gupta, S. B.1974. An Introduction to Tantric Buddhism. Calcutta: University of Calcutta.

Kats, J (ed). 1910. Sang Hyang Kamahāyānikan. An old Javanese Texts. Leiden: Martinus Nijhoff.

Kemper, Bernet, 1991. Monumental Bali, Introduction to Balinese Archaeology \& Guide to the Monuments. Singapora: Periplus Edition.

Kern, J.H.C. and W.H. Rasser. 1982. Śiva dan Buddha, Dua Karangan Tentang Śivaisme dan Buddhisme di Indonesia, (tr. KITLV dan LIPI). Jakarta: Djambatan..

Krom, N.J., 1923. Inleiding tat de Hindoe-Javaansche Kunst, Tweede herziene druk. Deel I. Leiden: 's-Gravenhage, Martinus Nijhoff.

Kumar, Dr. Bachchan, (Ed.). 2001. Glimpses of Early Indo-Indonesia Culture, Collected Papers of Himansu Bhusan Sarkar. New Delhi: Indira Gandhi National Centre For Arts, Aryan Book International.

Lěvi, Sylvain. 1933. Sanskrit Texts From Bali. Baroda.

Mantra, Ida bagus Made. 1955. Hindu Literature and Religion in Indonesia, (Thesis Submitted for the Degree of Doctor of Philosophy), Calcutta: Visva Bharati University.

Murti, T.R.V. 2003. The Central Philosophy of Buddhism, A Study of Mādhyamika System. Delhi: Munshiram Manoharlal.

Santoso, Soewito. 1975. Sutasoma A Study in Javanese Vajrayana, Delhi: International Academy of Indian Culture.

Sarkar, H.B. 1980. Litterary Heritage of South-East Asia. Calcutta:. Firma KLM. 
Sharma, R.C. (eds). 2004. Interaction Between Brāhmanical and Buddhist Art. Delhi: D.K. Printworld.

Woodroffe, Sir John. 1998. Sakti and Sakta, Madras: Ganesh \& Co.

Widnya, I Ketut. 2005. Evolution of Siva-Buddha Cult in Indonesia (Thesis Submitted for the Degree of Doctor of Philosophy), Delhi: University of Delhi.

Yeshe, Lama Thubten. 2001. Introduction to Tantra. Boston: Wisdom Publications. Zoetmulder, P.J. 1968. Old Javanese-English Dictionary. Leiden: s'gravenhageMartinus Nijhoff. 